OPEN ACCESS

Edited by:

Guilhem Janbon,

Institut Pasteur, France

Reviewed by:

Elizabeth R. Ballou,

University of Birmingham,

United Kingdom

John C. Panepinto,

University at Buffalo, United States Jennifer Geddes-McAlister,

University of Guelph, Canada

Livia Kmetzsch,

Federal University of Rio Grande do

Sul, Brazil

*Correspondence:

Yingchun Xu

xycpumch@139.com

Tianshu Sun

sun_tianshu@163.com

${ }^{\dagger}$ These authors have contributed equally to this work

Specialty section:

This article was submitted to

Fungal Pathogenesis,

a section of the journal

Frontiers in Cellular and

Infection Microbiology

Received: 15 March 2021

Accepted: 27 July 2021

Published: 12 August 2021

Citation:

Sun T, Li Y, Li Y, Li H, Gong Y, Wu J, Ning Y, Ding C and Xu Y (2021)

Proteomic Analysis of Copper

Toxicity in Human Fungal Pathogen

Cryptococcus neoformans.

Front. Cell. Infect. Microbiol. 11:662404.

doi: $10.3389 /$ fcimb.2021.662404

\section{Proteomic Analysis of Copper Toxicity in Human Fungal Pathogen Cryptococcus neoformans}

\author{
Tianshu Sun ${ }^{1,2 *}$, Yanjian $\mathrm{Li}^{3 \dagger}$, Yingxing $\mathrm{Li}^{1,2}$, Hailong $\mathrm{Li}^{4}$, Yiyi Gong ${ }^{1}$, Jianqiang $\mathrm{Wu}^{1}$, \\ Yating Ning ${ }^{2,5,6}$, Chen Ding ${ }^{3}$ and Yingchun $X u^{2,5 *}$

\begin{abstract}
${ }^{1}$ Medical Research Centre, State Key Laboratory of Complex Severe and Rare Diseases, Peking Union Medical College Hospital, Chinese Academy of Medical Science, Beijing, China, ${ }^{2}$ Beijing Key Laboratory for Mechanisms Research and Precision Diagnosis of Invasive Fungal Diseases, Beijing, China, ${ }^{3}$ College of Life and Health Sciences, Northeastern University, Shenyang, China, ${ }^{4}$ National Health Commission Key Laboratory of AIDS Immunology (China Medical University), National Clinical Research Center for Laboratory Medicine, The First Affiliated Hospital of China Medical University, Shenyang, China, ${ }^{5}$ Department of Clinical Laboratory, State Key Laboratory of Complex Severe and Rare Diseases, Peking Union Medical College Hospital, Peking Union Medical College, Chinese Academy of Medical Sciences, Beijing, China, ${ }^{6}$ Graduate School, Chinese Academy of Medical Sciences and Peking Union Medical College, Beijing, China
\end{abstract}

Cryptococcus neoformans is an invasive human fungal pathogen that causes more than 181,000 deaths each year. Studies have demonstrated that pulmonary C. neoformans infection induces innate immune responses involving copper, and copper detoxification in $C$. neoformans improves its fitness and pathogenicity during pulmonary $C$. neoformans infection. However, the molecular mechanism by which copper inhibits $C$. neoformans proliferation is unclear. We used a metallothionein double-knockout $C$. neoformans mutant that was highly sensitive to copper to demonstrate that exogenous copper ions inhibit fungal cell growth by inducing reactive oxygen species generation. Using liquid chromatography-tandem mass spectrometry, we found that copper down-regulated factors involved in protein translation, but up-regulated proteins involved in ubiquitin-mediated protein degradation. We propose that the down-regulation of protein synthesis and the up-regulation of protein degradation are the main effects of copper toxicity. The ubiquitin modification of total protein and proteasome activity were promoted under copper stress, and inhibition of the proteasome pathway alleviated copper toxicity. Our proteomic analysis sheds new light on the antifungal mechanisms of copper.

Keywords: Cryptococcus neoformans, copper toxicity, ROS, quantitative proteomics, ubiquitin degradation

\section{INTRODUCTION}

Cryptococcus neoformans is a commonly inhaled fungal pathogen. It infects approximately 1 million individuals annually (Maziarz and Perfect, 2016) and causes over 181,000 deaths (Agustinho et al., 2018). Fifteen percent of AIDS-related deaths were reported to be associated with cryptococcosis. It also affects immunocompetent individuals (Datta et al., 2009; Kronstad et al., 2011; Andreou et al., 2020). The high mortality of cryptococcosis poses a huge burden, especially in medically deficient

Abbreviations: $\mathrm{Cu}$, copper; LC-MS/MS, liquid chromatography-tandem mass spectrometry; NAC, N-acetylcysteine; ROS, reactive oxygen species. 
areas (Agustinho et al., 2018). Improved therapies are required to overcome challenges such as drug cost and availability, toxic side effects, lengthy treatment regimens, and resistance.

With the emergence of drug-resistant isolates, new antimicrobial agents, including metals, have received increasing attention. Copper $(\mathrm{Cu})$, along with silver, gold, iron, zinc, and magnesium, has good antimicrobial properties (German et al., 2016; Vimbela et al., 2017). The in vitro antimicrobial properties of metals are mainly attributed to their electron transport function. $\mathrm{Cu}$ and $\mathrm{Cu}$ alloys are now widely used as antimicrobials in healthcare settings because of their "contact killing" antimicrobial activity. $\mathrm{Cu}$ was registered as the first solid antimicrobial material by the US Environmental Protection Agency (Grass et al., 2011). Copper can exist in two forms in cells: oxidized copper $\left(\mathrm{Cu}^{2+}\right)$ or reduced cuprous $\left(\mathrm{Cu}^{+}\right)$(Gaetke and Chow, 2003). Several enzymes, such as lysyl oxidase, tyrosinase, cytochrome c oxidase, contain $\mathrm{Cu}$, which acts as an electron donor/acceptor, alternating between oxidation and reduction (Karlin, 1993). However, the redox properties of $\mathrm{Cu}$ can also cause cell damage.

Metals also play an essential role in innate defense (Hood and Skaar, 2012). Copper aids in the host resistance against both bacteria and fungi ( $\mathrm{Li}$ et al., 2019). Down-regulating the $\mathrm{Cu}$ transporter ATP7A on the lysosome and phagosome membranes was shown to inhibit the phagocytosis of bacteria and fungi by macrophages (White et al., 2009; Shen et al., 2018). After Cu supplementation, neutrophilic counts returned to normal in a patient with Coeliac disease (Khera et al., 2016). Ceruloplasmin, a multicopper oxidase, was elevated during infection with pathogens (Besold et al., 2016).

Pathogens have evolved complex $\mathrm{Cu}$ detoxification mechanisms to survive in their hosts. They can be divided into two aspects: $\mathrm{Cu}$ efflux systems and $\mathrm{Cu}$ sequestration (Chaturvedi and Henderson, 2014). Mycobacterium tuberculosis uses P-type ATPases (CtpC and $\mathrm{CtpV}$ ) and the metallothionein MymT to resist Cu toxicity (Neyrolles et al., 2013). Defects in the Cu transporter CopA and the polycopper oxidase $\mathrm{CueO}$ in Campylobacter jejuni reduced its colonization of avian hosts (Gardner and Olson, 2018). Candida albicans adapts to high $\mathrm{Cu}$ levels by regulating the metallothioneins Cup1 and Crd2 through CaAce1/Cup (Ballou and Wilson, 2016). C. neoformans regulates $\mathrm{Cu}$ metabolism using $\mathrm{Cuf1}$ to maintain $\mathrm{Cu}$ homeostasis (Ding et al., 2011; Jiang et al., 2011; Raja et al., 2013; Kosman, 2018). C. neoformans response to $\mathrm{Cu}$ stress was found to be activated upon lung invasion (Sun et al., 2014; Garcia-Santamarina and Thiele, 2015). Impairments in both metallothionein genes, CMT1 and CMT2, reduce virulence during pulmonary infection (Ding et al., 2013; Ding et al., 2014). The membrane $\mathrm{Cu}$ importer CTR4 in C. neoformans was down-regulated under $\mathrm{Cu}$ stress and it has been recognized as an indicator of $\mathrm{Cu}$ stress during pulmonary C. neoformans infections (Sun et al., 2014).

It has been reported that the toxicity of Cu to cells stems from its ability to induce reactive oxygen species (ROS) production (Gaetke and Chow, 2003). $\mathrm{Cu}^{2+}$ can be reduced to $\mathrm{Cu}^{+}$in the presence of reducing agents such as superoxide, ascorbic acid, and glutathione $(\mathrm{GSH}) . \mathrm{Cu}^{+}$catalyzes the conversion of hydrogen peroxide $\left(\mathrm{H}_{2} \mathrm{O}_{2}\right)$ to form hydroxyl radicals $(\mathrm{OH} \cdot)$ via the Haber-Weiss reaction (Bremner, 1998). The antimicrobial activity of $\mathrm{Cu}$-induced ROS was reported to involves membrane breakdown, respiratory inhibition, protein inactivation, and DNA degradation (Hans et al., 2015). Cu toxicity in C. neoformans has been investigated at the transcriptome level (Garcia-Santamarina et al., 2018), but little is known about how $\mathrm{Cu}$ modulates protein expression in fungal cells. In this study, we investigated the antifungal action of $\mathrm{Cu}$ by assessing proteomic changes using liquid chromatography-tandem mass spectrometry (LC-MS/MS).

\section{METHODS}

\section{Strains and Medium}

Cryptococcus neoformans var. grubii (serotype A) H99, was used as the wildtype strain for the experiment. $c m t 1 / 2 \Delta \Delta$ is a mutant C. neoformans strain on wild-type strain H99. The mutant is generated by knocking out both CMT1 and CMT2, which encode metallothioneins, with the selection markers being NAT and NEO (Ding et al., 2013). The cells were routinely grown in yeast extract peptone dextrose medium (YPD: $1 \%$ yeast extract, $2 \%$ peptone, and $2 \%$ dextrose). $\mathrm{CuSO}_{4}$ (final concentrations: 0.5 or 1 $\mathrm{mM}$ ) was added to induce $\mathrm{Cu}$ stress. $\mathrm{N}$-acetylcysteine (NAC; final concentrations: 30,40 , or $50 \mathrm{mM}$ ) was added to block ROS production. Colony images were captured using ImageQuant LAS 500 (GE, Boston, MA, USA).

\section{ROS Measurement}

Intracellular ROS levels were measured using a ROS assay kit (CA1410; Solarbio, Beijing, China). Overnight cultures of cmt1/ $2 \Delta \Delta$ were diluted in fresh YPD medium to an optical density at 600 $\mathrm{nm}$ of 0.2 . The cells were treated with 0.5 or $1 \mathrm{mMCu}$ at $30^{\circ} \mathrm{C}$ for $4 \mathrm{~h}$ $(n=3)$. The cells were then collected and washed twice in phosphatebuffered saline (PBS). Next, about $2 \times 10^{7}$ cells were stained with 20 $\mu \mathrm{M} 2^{\prime}, 7^{\prime}$-dichlorofluorescin diacetate (DCFH-DA) for $1 \mathrm{~h}$. DCFHDA (non-fluorescent) was hydrolyzed to dichlorofluorescin (DCFH) after entering cells. When DCFH is in the presence of ROS, it is oxidized to dichlorofluorescein (DCF), which is a strong green fluorescent substance. Fluorescence intensity was measured using microplate luminometers (Varioskan Flash; Thermo Fisher Scientific, Waltham, USA), with excitation at $488 \mathrm{~nm}$ and emission at $525 \mathrm{~nm}$. The intracellular ROS level is shown as fluorescence value divided by the absorbance at $600 \mathrm{~nm}$.

\section{Real-Time PCR}

$c m t 1 / 2 \Delta \Delta$ was cultured in YPD medium and treated with 0.5 $\mathrm{mM} \mathrm{CuSO}_{4}$ or both $0.5 \mathrm{mM} \mathrm{CuSO}_{4}$ and $30 \mathrm{mM} \mathrm{NAC}(\mathrm{n}=3)$. RNA samples used for real-time PCR were isolated using TRIzol reagent (Thermo Fisher Scientific, Waltham, MA, USA) followed by TURBO DNase I treatment (Thermo Fisher Scientific) to eliminate DNA contamination. One microgram of total RNA was reverse-transcribed into cDNA using the GoScript Reverse Transcription System (Promega, Madison, WI, USA). Real-time PCR was performed using a CFX Connect thermal cycler (BioRad, Hercules, CA, USA). The data were analyzed using the $2^{-\Delta \Delta C t}$ method. ACT1 was used as the loading control. Table S1 lists the primer pairs used. 
Protein Extraction, Digestion, and Labeling $c m t 1 / 2 \Delta \Delta$ was cultured in YPD medium and treated with 0.5 $\mathrm{mM} \mathrm{Cu}$ or both $0.5 \mathrm{mM} \mathrm{Cu}$ and $30 \mathrm{mM}$ NAC. The cells were washed twice in PBS and proteins were then extracted using lysis buffer (7 M urea, $2 \mathrm{M}$ sulfourea, and 0.1\% CHAPS) with a protease inhibitor cocktail using a Precellys Evolution tissue homogenizer (Bertin, Montigny-le-Bretonneux, France). Protein concentrations were determined using the Bradford method. Dithiothreitol was added to a $100 \mu \mathrm{g}$ protein extract to a final concentration of $25 \mathrm{mM}$, and the mixture was incubated at $37^{\circ} \mathrm{C}$ for $1 \mathrm{~h}$. Iodoacetamide (163-2109; Bio-Rad) was then added to a final concentration of $50 \mathrm{mM}$ and the mixture was incubated at room temperature in the dark for 30 min. Next, the mixture was sieved through a $10-\mathrm{kDa}$ filter (UFC501096; MilliporeSigma, Burlington, MA, USA) and washed thrice in $0.2 \mathrm{M}$ triethylammonium bicarbonate (TEAB, T7408, MilliporeSigma) buffer. The protein was digested overnight with $2 \mu \mathrm{g}$ trypsin (trypsin to protein mass ratio of $1: 50)$ at $37^{\circ} \mathrm{C}$. Next, the peptides were labeled using isobaric tags for relative and absolute quantitation (iTRAQ) reagents (4381663; AB Sciex, Framingham, MA, USA) desalted using a hydrophilic/lipophilic balanced column (WAT094226; Waters, Milford, MA, USA), and vacuum-dried. The iTRAQ-labeled peptides were dissolved in $2 \%$ acetonitrile, and then fractionated using high-pH high-performance liquid chromatography (HPLC; Xbridge Peptide BEH C18 column, $4.6 \mathrm{~mm} \times 150 \mathrm{~mm}, 3.5 \mu \mathrm{m}$; Waters). The elution gradient was $95-5 \%$ phase A (2\% acetonitrile, $\mathrm{pH} 10)$ and $5-95 \%$ phase $\mathrm{B}$ ( $98 \%$ acetonitrile, $\mathrm{pH} 10$ ) for $60 \mathrm{~min}$. The eluted peptides were collected at a rate of one fraction per min. To shortening the loading time in the LC-MS/MS analysis, 60 offline fractions were pooled into 10 fractions and lyophilized. All fractions were then combined for database searching.

\section{LC-MS/MS Analysis}

Dried peptides were re-suspended in $0.1 \%$ formic acid and loaded onto a reversed-phase C18 analytical column $(75 \mu \mathrm{m} \times$ $150 \mathrm{~mm}, 3 \mu \mathrm{m}$, custom-made in our lab). Elution was accomplished using a constant flow $(0.6 \mu \mathrm{L} / \mathrm{min})$ of buffer A $(0.1 \%$ formic acid) and buffer B ( $80 \%$ acetonitrile) over a gradient from $5 \%$ to $38 \%$ for $120 \mathrm{~min}$. The polypeptide mixture was analyzed using an Orbitrap Q-Exactive Plus mass spectrometer (Thermo Fisher Scientific). Each full scan was a high-speed signal-dependent scan. The first-level full scan was performed from 350 to $1,800 \mathrm{~m} / z$ at 70,000 resolution, and automatic gain control was set at $3 \mathrm{e} 6$. The second-level scan was performed from 100 to $1,800 \mathrm{~m} / z$ at 17,500 resolution, and automatic gain control was set at 1e5. Higher-energy collisional dissociation mode was used, with a normalized collision energy of $32 \%$ and a scanning time of $120 \mathrm{~min}$.

\section{Database Search and Bioinformatics Analysis}

The LC-MS/MS data were searched against the UniProt Cryptococcus neoformans H99 database (https://www.uniprot. org/proteomes/UP000010091), which provide resource of protein sequence and functional information, using Mascot (version 2.5.1) and Scaffold (version 4.6.2) software, assuming the digestion enzyme trypsin and two missed cleavages at maximum. The MS tolerance was $10 \mathrm{ppm}$ and the fragment ion mass tolerance was $0.02 \mathrm{Da}$. Carbamidomethyl of cysteine and iTRAQ-8plex of lysine and the n-terminus were specified in Mascot as fixed modifications. Oxidation of methionine, acetyl of the n-terminus and iTRAQ-8plex of tyrosine were specified in Mascot as variable modifications. Protein identifications were accepted as contained at least 2 identified peptides. Protein probabilities were assigned by the Protein Prophet algorithm (Nesvizhskii et al., 2003).

Proteins were considered to be differentially expressed if the ratio $<0.769$ or $>1.3$ (foldchange $>1.3$ ) (Zhu et al., 2020; Jiang et al., 2020) and FDR corrected $q$-value $<0.05$. The quantified proteins were annotated by Gene Ontology (GO) and Kyoto Encyclopedia of Genes and Genomes (KEGG) analyses. GO analysis was performed using clusterProfiler (version 3.14.0) in $\mathrm{R}$ (version 3.6.1) (Yu et al., 2012). C. neoformans gene ontology data were downloaded from Annotation Hub. The EnrichGO and compareCluster functions were used for the analyses. KOBAS (version 3.0) was employed to perform the KEGG analysis (Li et al., 2019).

\section{Parallel Reaction Monitoring Assay}

PRM, a reliable targeted LC-MS analysis, was used as a validation of the quality of iTRAQ-proteomic data in this research, considering antibodies to target proteins were not easy to be acquired in C. neoformans. It can provide higher accuracy, sensitivity and reproducibility data compared with nontargeted profile (Manes and Nita-Lazar, 2018). The proteins were reduced with $0.25 \mathrm{M}$ dithiothreitol, alkylated with $0.5 \mathrm{M}$ iodoacetamide, cleaned thrice with $0.2 \mathrm{M}$ TEAB, digested overnight with trypsin (the ratio of trypsin to protein was 1:50), then cleaned thrice with $0.5 \mathrm{M}$ TEAB and collected by centrifugation. Solid-phase extraction was performed using a ZipTip C18 column (Millipore, USA). After separation using an EASY-nLC liquid phase, the proteins were subjected to low-pH reversed-phase C18 capillary chromatography $(150 \mu \mathrm{m} \times 150$ $\mathrm{mm}, 1.9 \mu \mathrm{m})$. Phase A consisted of $0.1 \%$ formic acid and the phase $\mathrm{B}$ consisted of $80 \%$ acetonitrile and $0.1 \%$ formic acid. The elution gradient was $13-38 \%$, the total elution time was $60 \mathrm{~min}$, and the flow rate was $0.6 \mu \mathrm{L} / \mathrm{min}$. The polypeptide mixture was identified using an Orbitrap Q-Exactive Plus mass spectrometer. High-sensitivity and data-dependent acquisition scanning modes were used, and the scanning time was $120 \mathrm{~min}$. The first-level full scan was performed from 300 to $1500 \mathrm{~m} / z$ at 60,000 resolution, with collision energy of $30 \%$. The second-level scan was performed at 15,000 resolution. PRM was conducted according to the data-dependent acquisition scanning results. Each full scan was followed by 25 targeted scans, and the scanning time was $60 \mathrm{~min}$. The first-level full-scan was performed from 300 to $1250 \mathrm{~m} / z$ at 60,000 resolution and automatic gain control was set at $3 \mathrm{e} 6$, with a normalized collision energy of $28 \%$ and a maximum injection time of $80 \mathrm{~ms}$. The resolution of the secondary scan was 30,000 . The mixed essential-spectral data were retrieved by Proteome Discoverer (version 2.1). The 
retrieval parameters were obtained from the UniPort Cryptococcus neoformans $\mathrm{H} 99$ database. Mass errors of parent and fragmentation ions were $10 \mathrm{ppm}$ and $0.05 \mathrm{Da}$, respectively. Quality control parameters included polypeptide false discovery rate $<1.0 \%$ and protein false discovery rate $<1.0 \%$, with each protein identified to at least one specific polypeptide. Pooled peptide samples $(2 \mu \mathrm{g}$ of each sample) were subjected to LC-MS/ MS analysis for preparation of the spectrum library. Skyline (version 4.1.1.11725) was used to process the MS data.

\section{Western Blot}

$c m t 1 / 2 \Delta \Delta$ was treated with $0.5 \mathrm{mM} \mathrm{Cu}$ in YPD medium at $30^{\circ} \mathrm{C}$ for $4 \mathrm{~h}(\mathrm{n}=3)$. The cells were washed twice in cold PBS, and then the proteins were extracted in lysis buffer (7 M urea, $2 \mathrm{M}$ sulfourea, and $0.1 \%$ CHAPS) with a proteinase inhibitor and phenylmethylsulfonyl fluoride (PMSF). Next, $30 \mu \mathrm{g}$ of protein was used for sodium dodecyl sulfate-polyacrylamide gel electrophoresis. Western blot assays were performed using an anti-ubiquitin antibody $(1: 1,000 ; 3933$; Cell Signaling Technology, Boston, MS, USA), anti-histone H3 antibody (1:1,000; 4499S; Cell Signaling Technology), and goat antirabbit IgG $(\mathrm{H}+\mathrm{L})$ secondary antibody (1:5,000; A16096; Thermo Fisher Scientific). The results were imaged using ChemiDoc XRS+ (Bio-Rad, USA).

\section{Proteasome Activity Assay}

$c m t 1 / 2 \Delta \Delta$ was treated with $0.5 \mathrm{mM} \mathrm{Cu}, 0.5 \mathrm{mM} \mathrm{Cu}$ and $30 \mathrm{mM}$ $\mathrm{NAC}$, or $1 \mathrm{mM} \mathrm{Cu}$ in YPD medium at $30^{\circ} \mathrm{C}$ for $4 \mathrm{~h}(\mathrm{n}=3)$. Cells were washed twice in cold PBS, and then lysed using in $0.5 \%$ NP40. Proteasome activity was assessed using a proteasome activity assay kit (ab107921; Abcam, Cambridge, MA, USA). The samples were mixed with proteasome substrate and incubated at $37^{\circ} \mathrm{C}$. The proteasome activity units (relative to the standard fluorescence intensity) were determined according to the fluorescence consumed from 30 to 60 minutes of the reaction. Fluorescence intensity was measured using a multimode reader (SYNERGY-LX; BioTek, Winooski, VT, USA), with excitation at $350 \mathrm{~nm}$ and emission at $440 \mathrm{~nm}$.

\section{Growth Kinetics Assay}

$c m t 1 / 2 \Delta \Delta$ was shake cultured in YPD medium overnight at $30^{\circ} \mathrm{C}$. The cells were then treated with $0.5 \mathrm{mM} \mathrm{Cu}, 10 \mu \mathrm{g} / \mathrm{mL}$ proteasome inhibitor MG132 (HY-13259; MedChemExpress, Monmouth Junction, NJ, USA), or both $0.5 \mathrm{mM} \mathrm{Cu}$ and 10 $\mu \mathrm{g} / \mathrm{mL}$ MG132 in 96-well plates $(\mathrm{n}=3)$. The optical density at 600 $\mathrm{nm}$ of the initial culture system was 0.05 . The optical density of the cells was detected every $4 \mathrm{~h}$ to plot the growth curves.

\section{Statistics and Reproducibility}

Statistical analysis of ROS level, real-time PCR data, and proteasome activity data was performed in GraphPad Prism 6.0 software. Significant differences between two groups were determined by Student's t-test $\left({ }^{*} p\right.$ values $<0.05,{ }^{* *} p$ values $<0.01$, ${ }^{* * *} p$ values $\left.<0.005\right)$. comparison between multiple treatments was performed using ANOVA $\left({ }^{* *} p\right.$ values $\left.<0.005\right)$. All experiments were performed using three biological replicates to ensure reproducibility. Proteomic data reproducibility was analyzed using principal component analysis (PCA), using the $\mathrm{R}$ package ggplot2 (version 3.2.1). Two-tailed Fisher's exact tests were used to assess the GO and KEGG enrichment of the differentially expressed proteins against all identified proteins.

\section{Data Availability}

The mass spectrometry proteomics data have been deposited to the ProteomeXchange Consortium (http://proteomecentral. proteomexchange.org) via the iProX partner repository with the dataset identifier PXD024098 http://proteomecentral. proteomexchange.org/cgi/GetDataset?ID=PXD024098.

\section{RESULTS}

\section{Exogenous Cu Induces Intracellular ROS Generation in C. neoformans}

It was reported that the antimicrobial activity of $\mathrm{Cu}$ is associated directly with its oxidative characteristics (Vincent et al., 2018). The activities of superoxide dismutase, catalase and glutathione peroxidase, proteins associated with ROS metabolism, in $\mathrm{Cu}$ sensitive strain $c m t 1 / 2 \Delta \Delta$ were improved under copper stress (Sun et al., 2021). But whether ROS is the primary cause of cell death was unknown. We used $\mathrm{N}$-acetylcysteine (NAC), an aminothiol and synthetic precursor of intracellular cysteine and glutathione, as an ROS scavenger. It is a sulfhydryl-containing antioxidant that increases the free radical scavenging in cells. The metallothioneins double-knockout mutant $c m t 1 / 2 \Delta \Delta$ is very sensitive to $\mathrm{Cu}$ stress compared with wildtype strain $\mathrm{H} 99$, which was consistent with previous job (Ding et al., 2013), but it did not exhibit growth retardation when NAC was added to the medium. The growth of $\mathrm{H} 99$ and $c m t 1 / 2 \Delta \Delta$ were not affected by NAC treatment alone. With an increased $\mathrm{Cu}$ concentration, more NAC was required to neutralize the effects of $\mathrm{Cu}$ stress. When the $\mathrm{Cu}$ concentration was $0.5 \mathrm{mM}, 30 \mathrm{mM}$ NAC was required to prevent toxicity, and when it was raised to $1 \mathrm{mM}, 50 \mathrm{mM}$ NAC was required to prevent toxicity (Figure 1A). This preliminary experiment suggested that the generation of intracellular ROS is an important factor in $\mathrm{Cu}$ toxicity, although ROS-independent $\mathrm{Cu}$ toxicity remains possible (e.g., impairment of iron-sulfur protein biogenesis) (Brancaccio et al., 2017).

We used DCFH-DA fluorescent probes to image intracellular ROS under $\mathrm{Cu}$ stress, and we found a positive correlation between $\mathrm{Cu}$ concentration and intracellular ROS. Under $\mathrm{Cu}$ stress, $c m t 1 / 2 \Delta \Delta$ (which was deficient in the $\mathrm{Cu}$ detoxification factors CMT1 and CMT2) generated more ROS than the wildtype strain H99. However, Cu-induced intracellular ROS in both the wild-type and $c m t 1 / 2 \Delta \Delta$ strains was suppressed by NAC (Figure 1B). To assess whether NAC operates independent of chelating $\mathrm{Cu}$ ions during the $\mathrm{Cu}$ detoxification process, we assessed the expression of the membrane $\mathrm{Cu}$ importer CTR4, which is down-regulated under $\mathrm{Cu}$ stress, indicating high $\mathrm{Cu}$ concentration sensed by cells (Sun et al., 2014). CTR4 was downregulated in $c m t 1 / 2 \Delta \Delta$ under $\mathrm{Cu}$ treatment, regardless of whether NAC was added to the medium (Figure 1C). This indicated that the NAC action was attributable to its antioxidant activity rather than depletion of $\mathrm{Cu}$ ions. 
A

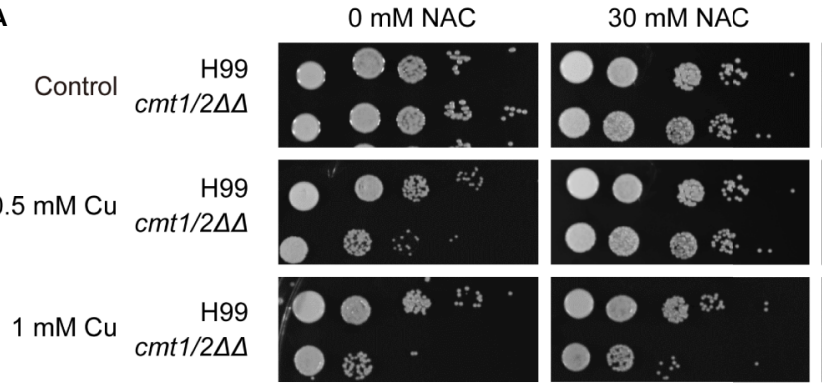

40 mM NAC

$50 \mathrm{mM} \mathrm{NAC}$

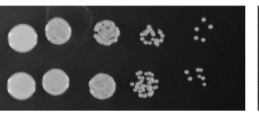

000 紫

$\begin{array}{llll:}0 & 0 & 0 & * \\ 0 & 0 & 0 & 0\end{array}$

$\begin{array}{llll:}0 & 0 & 0 & 0 \\ 0 & 0 & 0 & 0\end{array}$
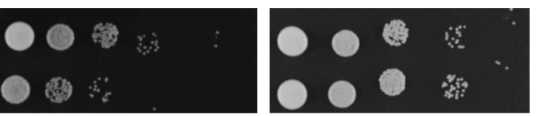

B

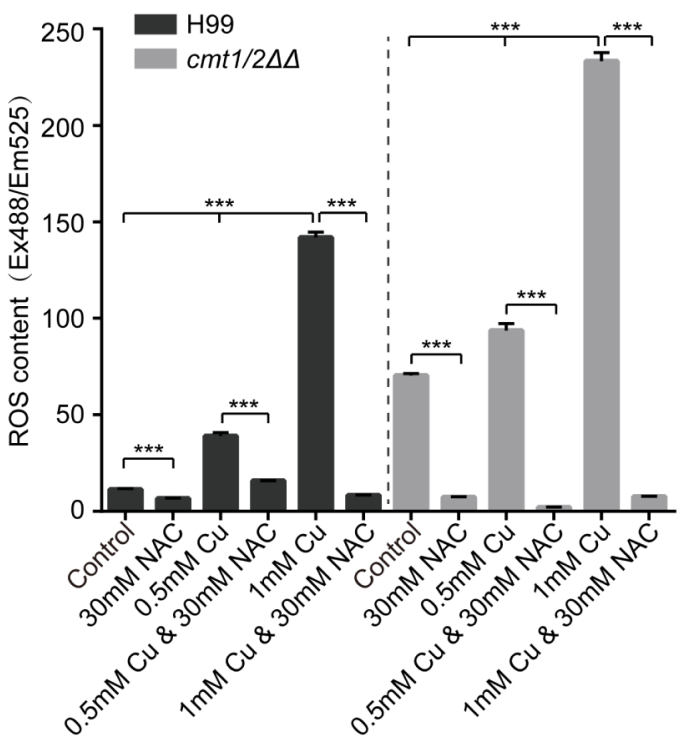

C

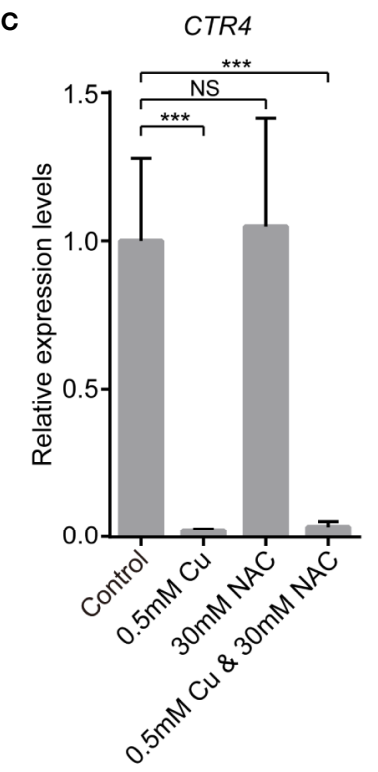

$c m t 1 / 2 \Delta \Delta$

FIGURE 1 | N-acetylcysteine reduces the ROS-toxicity induced by copper in Cryptococcus neoformans. (A) Growth of $C$ neoformans following treatment with Cu and $\mathrm{N}$-acetylcysteine (NAC). Clinically isolated wild-type C. neoformans strain $\mathrm{H} 99$ and the Cu-sensitive mutant cmt1/2 $\Delta \Delta$ were grown in yeast extract peptone dextrose (YPD) liquid medium overnight, serially diluted and cultured on agar medium at $30^{\circ} \mathrm{C}$ for 2 days. (B) Levels of intracellular ROS following treatment with $\mathrm{Cu}$ and NAC. Cells were treated with 0.5 or $1 \mathrm{mM} \mathrm{Cu}$ and NAC was added to scavenge ROS. The intracellular ROS level is shown as fluorescence intensity (Ex488/Em525) divided by the absorbance at $600 \mathrm{~nm}$. ${ }^{* * *} p$-value $<0.005$ ( $\left.n=3\right)$. (C) Relative expression of the Cu importer CTR4 in the Cu-sensitive mutant $c m t 1 / 2 \Delta \Delta$. Cells were treated with $0.5 \mathrm{mM} \mathrm{Cu}$ and/or $30 \mathrm{mM} \mathrm{NAC}$ and RNA was extracted and analyzed by real-time polymerase chain reaction. ${ }^{* * *} p$-value $<0.005(n=3)$. NS, not significant.

\section{Quantitative Proteomic Profile of C. neoformans Under Cu Stress}

Based on our previous work and the data presented in Figure 1 showing overall concordance regarding the responses to $\mathrm{Cu}$ and NAC between wild-type and $c m t 1 / 2 \Delta \Delta$ strains, we anticipated that $\mathrm{Cu}$-sensitive $c m t 1 / 2 \Delta \Delta$ would accurately reflect the overall response of $\mathrm{C}$. neoformans to $\mathrm{Cu}$ stress, but with a magnitude of changes more readily detectable at the proteomic level. We therefore used $c m t 1 / 2 \Delta \Delta$ to amplify the $\mathrm{Cu}$ stress response of C. neoformans in the whole proteome analysis. The cells were cultured to the logarithmic phase and then collected for protein extraction. To investigate the function of ROS in response to $\mathrm{Cu}$ treatment, the ROS scavenger NAC was added to the medium (Figure 2A). A total of 3,529 proteins were quantified by LC-MS/ MS (Table S2) and validated for mass accuracy (Figure S1). Principal component analysis suggested that the exposure groups could be differentially separated into three clusters (Figure 2B).
In the cells treated with $\mathrm{Cu}$ alone compared to untreated cells, 168 proteins were differentially expressed. In the cells treated with NAC plus $\mathrm{Cu}$ compared to $\mathrm{Cu}$ alone, 289 proteins were differentially expressed. In the cells treated with NAC plus $\mathrm{Cu}$ compared to untreated cells, 61 proteins were differentially expressed (ratio $<0.769$ or $>1.3$, FDR corrected $q$-value $<0.05$ ) (Figure 2C and Table S3). Among the two sets of differentially expressed proteins in control vs. $\mathrm{Cu}$ and $\mathrm{Cu}$ vs. Cu\&NAC comparisons, 95 proteins overlapped, and these were considered potential targets of $\mathrm{Cu}$-induced ROS (Figure 2D). Though 4 proteins were overlapped in the 3 pairs of comparisons, they all showed the different trend in control $v s$. Cu compared with control vs. Cu\&NAC. The expression of the 95 proteins (37 downregulated and 58 up-regulated under $\mathrm{Cu}$ stress) was normalized by NAC (Figure 2E). To verify the reliability of the iTRAQ quantitative proteomic analysis, 82 peptides (Table S4A) of 37 proteins that were notably differentially expressed and involved in 
A

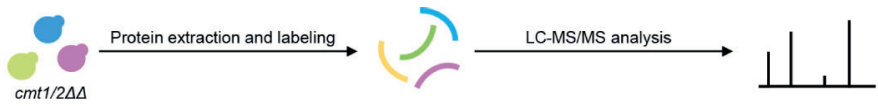

B

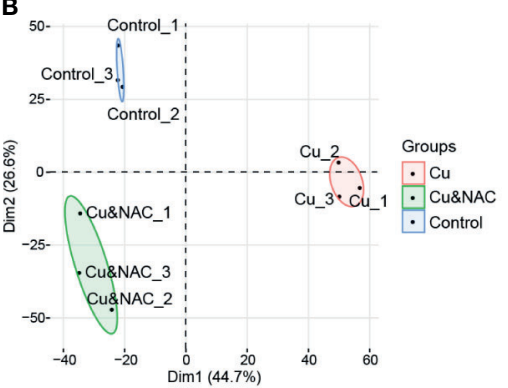

C
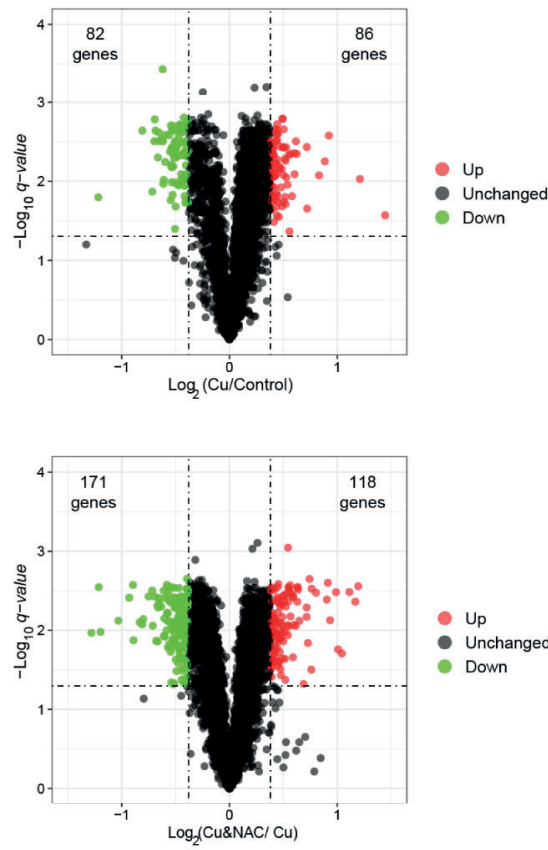

Up

- Unchanged

- Down
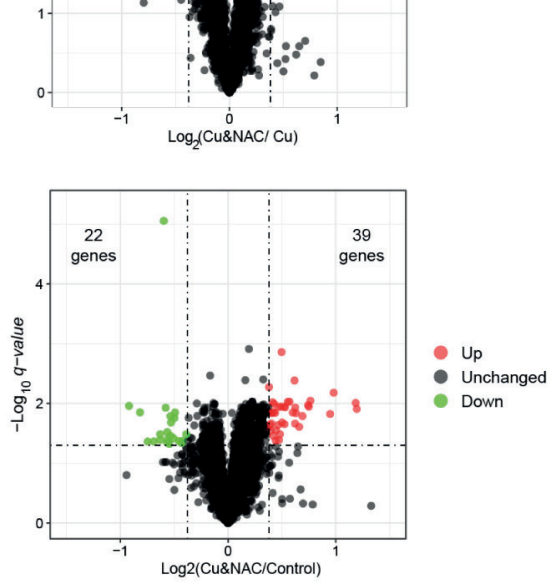
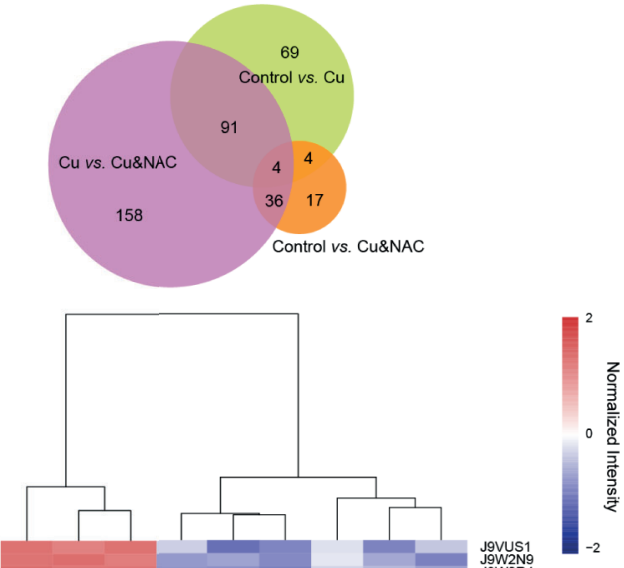

FIGURE 2 | Continued 
FIGURE 2 | iTRAQ quantitative proteomic analysis of the copper (Cu)-sensitive mutant cmt1/2 $\Delta \Delta$ following treatment with $\mathrm{Cu}$ or $\mathrm{Cu}$ and $\mathrm{N}$-acetylcysteine (NAC).

(A) Study flow diagram. The metallothionein double-knockout strain cmt1/2 $\Delta \Delta$ was grown in yeast extract peptone dextrose (YPD) liquid medium overnight and divided into three groups: an untreated (Control) group ( $n=3)$, a group exposed to $\mathrm{Cu}(n=3)$, and a group exposed to both Cu and NAC ( $n=3$ ). Cells grown to the logarithmic stage were lysed to extract proteins, which were digested into peptides, labeled, and assessed by liquid chromatography-tandem mass spectrometry (LC-MS/MS). (B) Principal component analysis (PCA) of proteomic data. Raw proteomic data were obtained using LC-MS/MS and analyzed using the R package ggplot2 (version 3.2.1). Each point in the figure represents a single sample and treatment groups are distinguished by color. (C) Volcano plots of differentially expressed proteins. Each point represents a protein. The $x$-axis represents the log2 transformation of the protein ratio between two groups. The $y$-axis represents the -log10 transformation of the FDR corrected $q$-values of the comparisons between the two groups. Green dots represent down-regulated proteins, red dots represent up-regulated proteins, and black dots represent unchanged proteins. (D) Venn diagram of differentially expressed proteins in the three pairs of comparisons (Cu vs. Control, Cu\&NAC vs. Cu and Cu\&NAC vs. Control). The size of each circle represents the number of differentially expressed proteins. (E) Heatmap of differentially expressed proteins common to the two comparisons. The $\mathrm{x}$-axis represents samples, and the $y$-axis represents proteins. The colors represent protein expression levels in the sample: the maximum value is red, and the minimum value is blue. According to the similarity of color between samples, the proteins were divided into two clusters: up-regulated under Cu stress and down-regulated under Cu stress.

the enrichment pathways were selected and measured by PRM (Yu et al., 2012). The target LC-MS/MS results were consistent with the iTRAQ-LC-MS/MS analysis for 35 of the 37 proteins ( ratio $<0.769$ or $>1.3$, FDR corrected $q$-value $<0.05$ ) (Table S4B). Most of the proteins identified were on the regression line in the correlation plot (Figure S2). The two unverified proteins, have not been found differentially expressed, may be limited by the reliability of the representative peptide segments.

\section{Gene Ontology Analysis of Differentially Expressed Proteins Under Cu Stress}

To globally analyze the molecular mechanism of Cu toxicity, based on the main functions of the differentially expressed proteins, we performed GO annotation using Blast2GO software (version 4.1.9) (Gotz et al., 2008) followed by enrichment analysis using the R cluster Profiler R package. The GO items with a $p$-value $<0.05$ were enriched in the biological process, cellular component, and molecular function categories from identified up-regulated proteins and down-regulated proteins under $\mathrm{Cu}$ stress, respectively (Ashburner et al., 2000). The up-regulated proteins were enriched in protein catabolic processes and ubiquitin-dependent protein catabolic processes. These changes mainly occurred in the proteasome complex, endopeptidase complex, peptidase complex, and catalytic complex, involving molecular functions related to endopeptidase activity, peptidase activity, catalytic activity acting on proteins, enzyme regulator activity, ATP binding and nucleotide binding. The down-regulated proteins were enriched in protein metabolic processes, translation, peptide biosynthetic process, amide biosynthetic process, organonitrogen compound biosynthetic process and branchedchain amino acid biosynthetic process. These changes mainly occurred in the ribosome, non-membrane-bound organelles, involving molecular functions related to structural constituents of ribosome, structural molecule activity and RNA binding (Figure 3). This indicated that the main features of the $\mathrm{Cu}$ toxicity were decreased in protein synthesis and increased protein degradation.

\section{Quantile-Based Clustering Analysis}

To clearly delineate the changes in protein expression in each treatment group, we constructed a heatmap of differentially expressed proteins (Figure 4A). The proteins were clustered according to their global expression characteristics and z-scores were calculated according to the normalized intensity in the horizontal and vertical dimensions separately. These z-scores were then clustered by one-way hierarchical clustering (Euclidean distance, average linkage clustering) using Genesis. Cluster membership was visualized using the "heatmap.2" function from the "gplots" package in R. As expected, the expression of proteins from cells treated with Cu plus NAC exhibited overall similarities to control cells, though the expression of some proteins was more similar to that in cells treated with $\mathrm{Cu}$ alone. $\mathrm{Cu}$-treated cells also exhibited some unique overlap with control cells that differed from the cells treated with Cu plus NAC, which may be partly attributable to the detoxification role of NAC in Cu stress.

Based on further hierarchical clustering, the differentially expressed proteins were divided into three clusters according to their distinctive expression characteristics. For each cluster, we grouped all the enriched functional categories along with their $p$ values (Figure 4B). The proteins in cluster 1 were down-regulated under $\mathrm{Cu}$ stress but not when $\mathrm{Cu}$ was administered with NAC; these proteins were mainly involved in biological processes related to translation, peptide synthetic process, amide synthetic process, peptide metabolic process, organonitrogen compound synthetic process and protein metabolic processes. The proteins in cluster 2 were up-regulated under $\mathrm{Cu}$ stress but not when $\mathrm{Cu}$ was administered with NAC; these proteins were mainly involved in protein catabolic process, ribosome biogenesis, organonitrogen compound catabolic process, ribonucleoprotein complex biogenesis, macromolecule catabolic processes, cellular compound biogenesis, organic substance catabolic process, rRNA processing, ubiquitin-dependent protein catabolic processes, ncRNA processing, cellular component organization or biogenesis, and protein metabolic process. The proteins in cluster 3 were down-regulated when $\mathrm{Cu}$ was administered with NAC; these proteins were related to glucan metabolism processes, response to oxidative stress, polysaccharide metabolic processes, carbohydrate metabolic processes and cellular catabolic process. In general, biological processes related to cluster 1 and cluster 2 proteins were the targets of ROS-dependent $\mathrm{Cu}$ toxicity.

\section{Ubiquitin-Mediated Proteolysis Is Up- Regulated in C. neoformans in Response to Cu Stress}

To identify the target pathways under $\mathrm{Cu}$ stress, we conducted a KEGG enrichment analysis in KOBAS (version 3.0) (Kanehisa et al., 2012). The proteins that were differentially expressed in cells treated with $\mathrm{Cu}$ alone compared to untreated control cells were enriched in three pathways: ribosome, proteasome, and protein processes in the endoplasmic reticulum. The differentially expressed proteins included ribosome and 


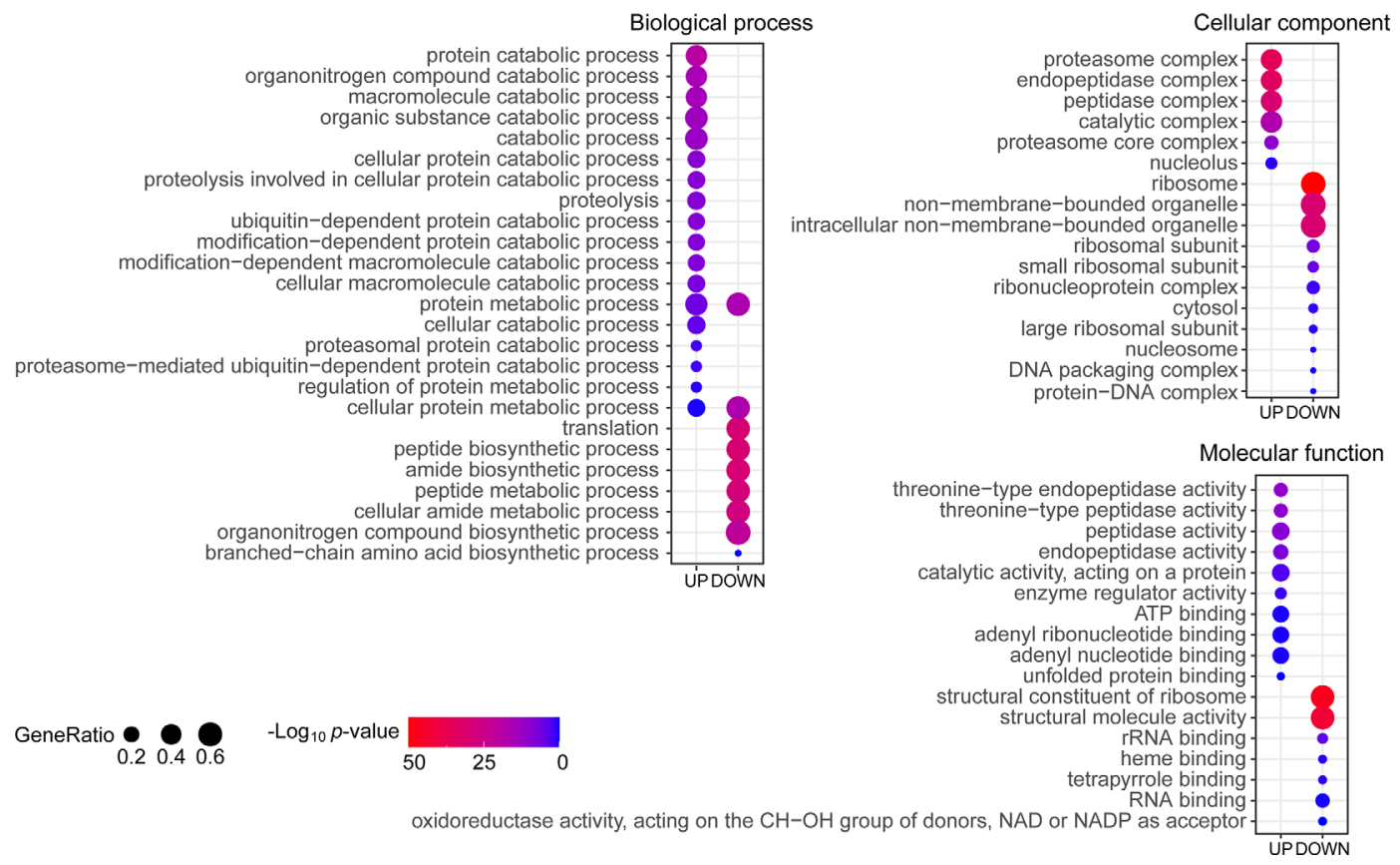

FIGURE 3 | Gene Ontology (GO) enrichment of differentially expressed proteins under copper (Cu) stress. The proteins were annotated with subcategory terms in the three GO categories: biological processes, cellular compartments, and molecular functions. For each category, a two-tailed Fisher's exact test was used to assess the enrichment of the differentially expressed protein against all identified proteins. The GO subcategories with a $p$-value $<0.05$ were considered significantly enriched and shown in the figure. The size of the bubbles represents the proportion of differentially expressed proteins in this subcategory among the total number of proteins in the corresponding category.

proteasome subunits, chaperones (HSP70 and HSP90), and glycogen metabolism-related protein (Ubx), ubiquitinconjugating enzyme variant MMS2 (p97), ER-associated protein catabolism-related protein ( $\mathrm{Npl} 4)$, ubiquitin fusiondegradation 1-like protein (Ufd1), and ubiquitin receptor (RAD23) (Table S5). Under Cu stress, 37\% of the ribosomal subunits were down-regulated, while $66 \%$ of the ubiquitin ligase complex and proteasomal subunits were up-regulated (Figure 5). Cells treated with $\mathrm{Cu}$ plus NAC compared to untreated control cells could prevent from these changes in ribosomal subunits. These findings suggest that $\mathrm{Cu}$-induced ROS alter protein synthesis and degradation processes.

Western blotting showed that $\mathrm{Cu}$ stress up-regulated the total ubiquitination in $c m t 1 / 2 \Delta \Delta$ (Figure 6A). The proteasome activity assay of $c m t 1 / 2 \Delta \Delta$ indicated increased proteasome activity after treatment with 0.5 or $1 \mathrm{mM} \mathrm{Cu}$, but unchanged when treated with both $0.5 \mathrm{mM} \mathrm{Cu}$ and $30 \mathrm{mM} \mathrm{NAC} \mathrm{(Figure} \mathrm{6B).} \mathrm{The} \mathrm{proteasome}$ inhibitor MG132 partially rescued the $c m t 1 / 2 \Delta \Delta$ growth inhibition after $\mathrm{Cu}$ treatment (Figure 6C), without changing the cell size and morphology (Figure S3) It indicates that promoting ubiquitinmediated proteolysis is a primary effect of $\mathrm{Cu}$ toxicity.

\section{DISCUSSION}

The toxicity of $\mathrm{Cu}$ to microbial pathogens has been used as a host defense strategy (Wiemann et al., 2017; Shen et al., 2018). In particular, $\mathrm{Cu}$ toxicity affects the virulence of $C$. neoformans during pulmonary infection (Ding et al., 2013), although the exact mechanism has not been fully elucidated. $\mathrm{Cu}$ can exist in an oxidized or reduced state, influencing its catalytic activity and contributing to ROS production (Kaur et al., 2019). We confirmed that intracellular ROS accumulated under $\mathrm{Cu}$ stress, especially in a $\mathrm{Cu}$-sensitive mutant that lacked metallothioneins. We hypothesize that $\mathrm{Cu}$ toxicity in C. neoformans was ROSdependent, as cell growth under $\mathrm{Cu}$ stress on plated media was not affected in the presence of a ROS inhibitor.

The Cu metabolic pathway is well understood in fungi (Smith et al., 2017; Garcia Silva-Bailao et al., 2018; Li et al., 2019; Raffa et al., 2019; Antsotegi-Uskola et al., 2020), but the molecular mechanisms underlying $\mathrm{Cu}$ toxicity have mainly been explored in bacteria. It was postulated that the targets of $\mathrm{Cu}$ toxicity are nucleic acids, structural and functional proteins, lipids, and inhibition of metabolic processes such as respiration and osmotic pressure, leading to cytolysis (Gaetke et al., 2014; Tan et al., 2017). To investigate the primary intracellular targets of $\mathrm{Cu}$-induced ROS, we compared the proteomic profiles of a $\mathrm{Cu}$ sensitive metallothionein double-knockout mutant among the $\mathrm{Cu}$ treatment, $\mathrm{Cu}$ plus NAC treatment groups, and control groups. The differentially expressed proteins under $\mathrm{Cu}$ stress were restored by NAC, an ROS scavenger, suggesting that ROS accumulation is a key factor in $\mathrm{Cu}$ toxicity.

We investigated the normalized intensity identified by MS of several proteins associated with ROS metabolism (Figure S4) 


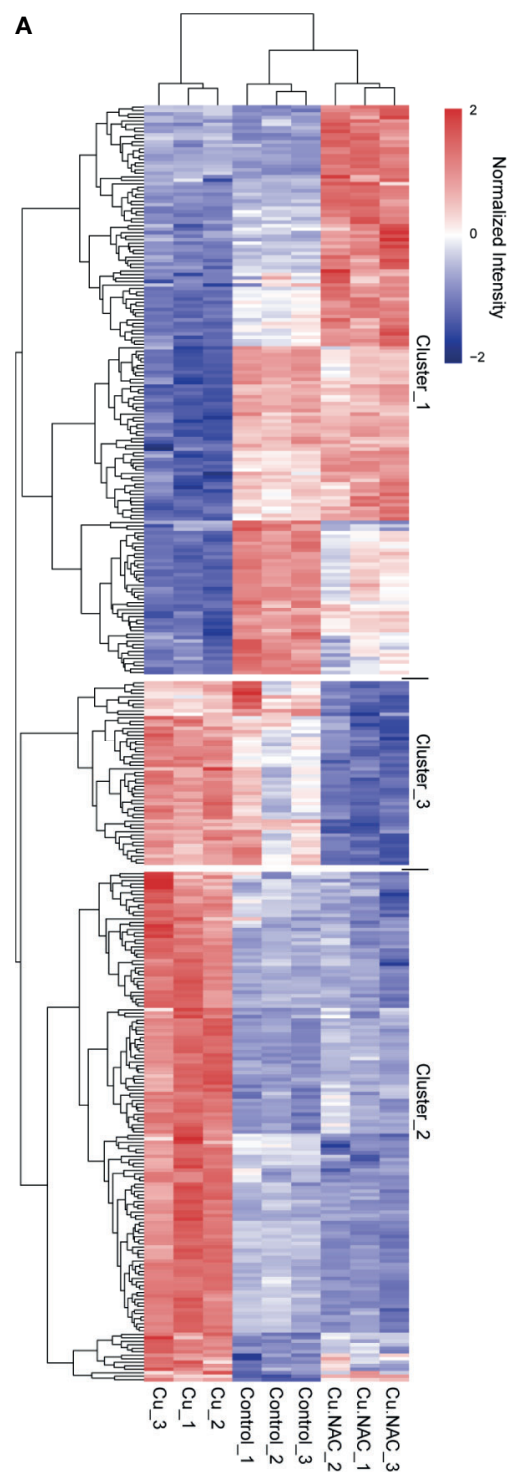

\section{B}

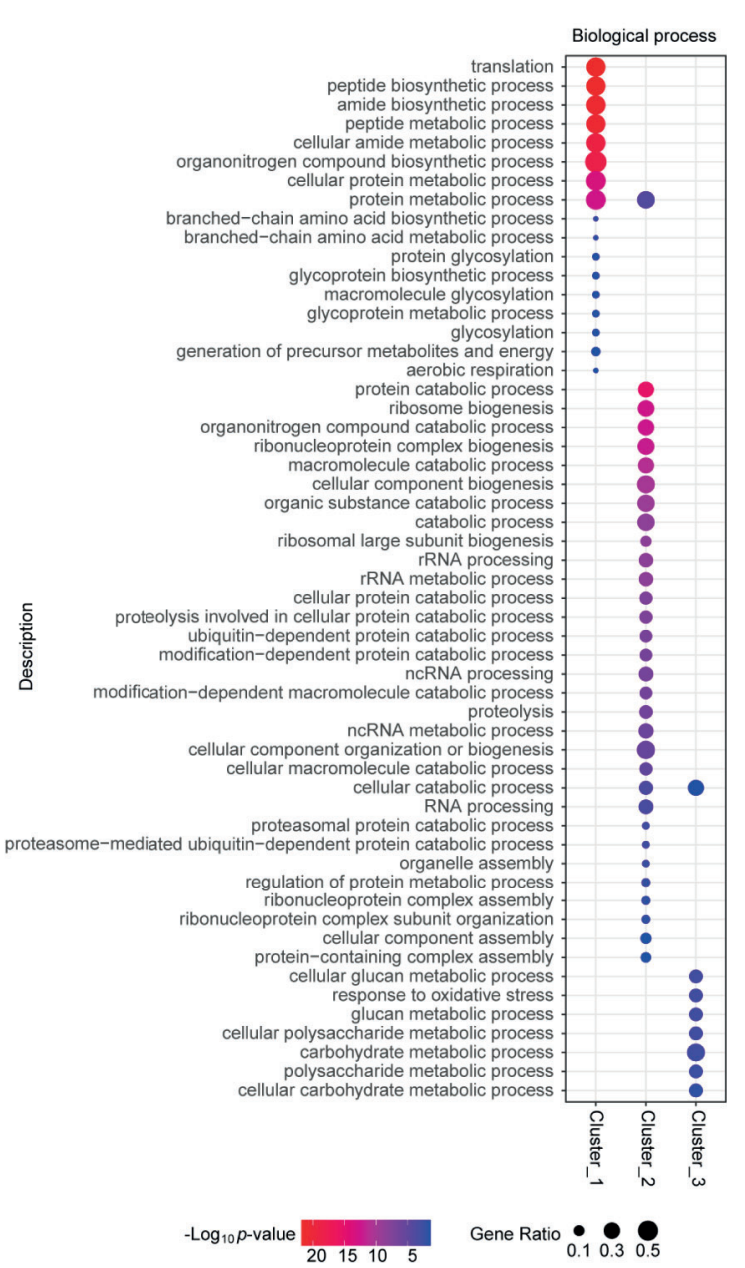

FIGURE 4 | Clustering-based Gene Ontology (GO) enrichment analysis of differentially expressed proteins following treatment with copper (Cu), Cu and Nacetylcysteine (NAC), or untreated (control). (A) Hierarchical clustering analysis of differentially expressed proteins under Cu stress. The $x$-axis represents the clustering of the samples and the $y$-axis represents the clustering of the differentially expressed proteins. The colors represent the relative expression levels of the proteins: the maximum value is red and the minimum value is blue. (B) Bubble diagram of enriched GO subcategories for the differentially expressed proteins in the three clusters, indicating $p$-values and protein ratios.

(Aguirre et al., 2006). For example, Sod2 (J9VWW9_CRYNH) was up-regulated during $\mathrm{Cu}$ treatment, but not in the presence of NAC, while Sod1 (J9VLJ9_CRYNH) was stably expressed under each treatment. These results were consistent with those reported in Histoplasma: Sod2 protects yeasts specifically from exogenous superoxide, while intracellular Sod1 eliminates endogenous ROS (Youseff et al., 2012). In addition, Catalase 3 and peroxidase Tsa1 (J9VH55_CRYNH) were significantly up-regulated under $\mathrm{Cu}$ treatment. Furthermore, $\mathrm{Cu}$ up-regulated the iron-sulfur cluster transporter Atm1 (J9VWU3_CRYNH) and iron-sulfur protein assembly co-chaperone HscB (J9VWP1_CRYNH). These results were consistent with the previous research
(Aguirre et al., 2006; Perez-Gallardo et al., 2013; GarciaSantamarina et al., 2017)

The role of $\mathrm{Cu}$ in DNA damage is controversial. Macomber and colleagues reported no DNA oxidative damage during $\mathrm{Cu}$ overload in Escherichia coli (Macomber et al., 2007). In our study, Cu downregulated processes involving the nucleosome and DNA packaging complex, as inferred based on expression changes in histone proteins. Histone ubiquitination and ADP glycosylation have been reported to be related to DNA repair (Thorslund et al., 2015; Cao et al., 2016; Uckelmann and Sixma, 2017; Liszczak et al., 2018). However, in our western blot analysis, the major differences in ubiquitination were concentrated in proteins with a molecular 

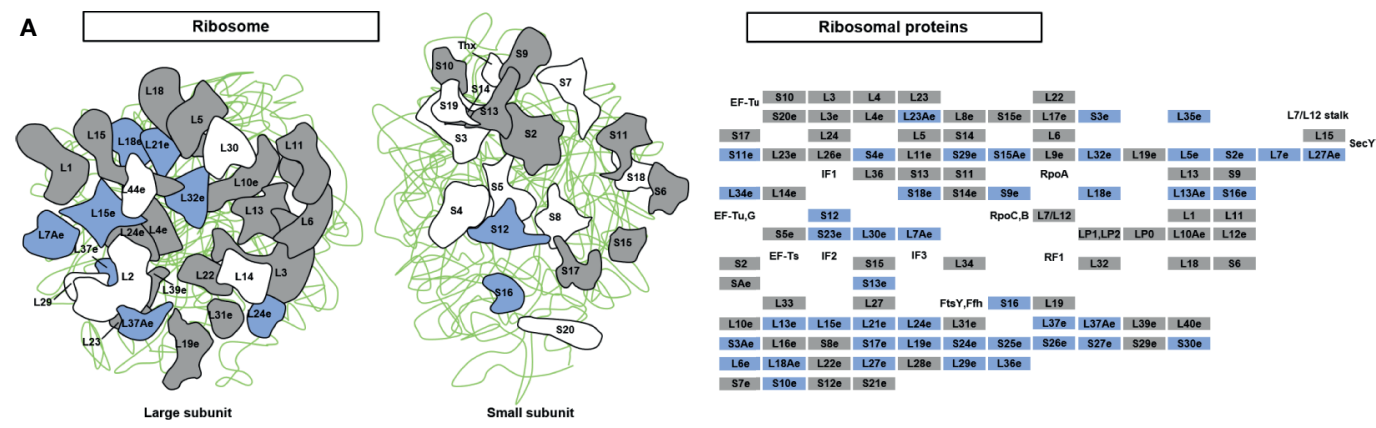

B ER-associated degradation (ERAD)

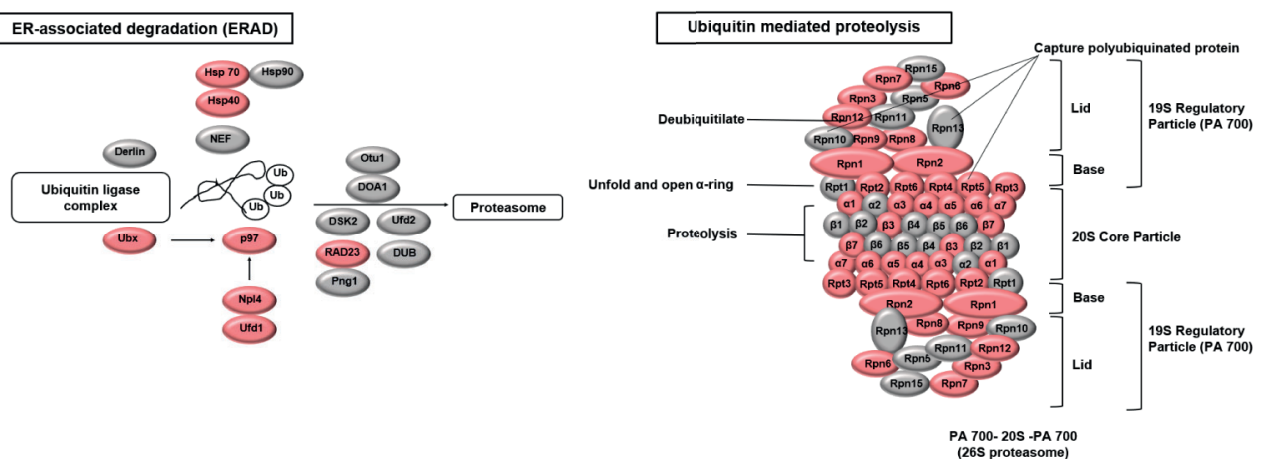

FIGURE 5 | Kyoto Encyclopedia of Genes and Genomes (KEGG) pathways targeted after copper (Cu)-induced accumulation of reactive oxygen species (ROS). (A) The ribosome pathway was down-regulated under Cu stress. The KEGG database was used to identify enriched pathways. A schematic diagram of ribosome subunits from the KEGG database is shown. All proteins in the ribosome pathway that were identified in the proteomic analysis are displayed in squares. Blue indicates down-regulated proteins $(q$-value $<0.05)$ and gray indicates unchanged proteins. (B) Two protein degradation pathways (endoplasmic reticulum-associated degradation and ubiquitin-mediated proteolysis) were up-regulated under Cu stress. All proteins identified in these two pathways that were identified in the proteomic analysis are displayed in ellipses. Red indicates up-regulated proteins $(q$-value $<0.05)$ and gray indicates unchanged proteins.

weight higher than that of histone. Thus, further experiments are required to explore the effect of $\mathrm{Cu}$ stress on DNA.

The spatial distribution of ROS formation suggests that RNA is more likely to be damaged than DNA. We did not confirm the stability of RNA under Cu stress, but research in E. coli has shown that oxidative stress can disrupt translation and damage ribosomal RNA. When the 70S and 23S subunits, which harbor the peptidyl transferase center, were oxidized, cells lost translation activities related to ribosomal protein L12 (Willi et al., 2018). These results are consistent with our data, which showed that most of the ribosome subunits were down-regulated under $\mathrm{Cu}$ stress. Our functional annotation analysis also suggested that up-regulated rRNA biogenesis and U3 small nucleolar RNA-associated proteins may be related to the response to $\mathrm{Cu}$ stress.

According to our data, $\mathrm{Cu}$ stress down-regulated protein synthesis and up-regulated protein degradation in C. neoformans, while NAC prevented these changes, suggesting that disruption of protein homeostasis is the main effect of $\mathrm{Cu}$-induced ROS. Regarding down-regulating protein synthesis, in E. coli, ribosomes are inhibited by gold nanoparticles, which prevent ATPase and tRNA binding (Cui et al., 2012). Additionally, the key regulatory role that ribosomes play in cell proliferation (Wilson, 2014), indicates that the down-regulation of the ribosomal subunits may be a key limiting factor in cell growth. Consistently, proteomic analysis of Saccharomyces cerevisiae showed that increased intracellular ROS suppressed global protein synthesis, which may be regulated by modulating the redox state of proteins (Topf et al., 2018). Furthermore, $\alpha$ subunit of eukaryotic initiation factor 2 (eIF $2 \alpha$ ) was identified to be the translational repressor in response to oxidative stress in C. neoformans (Leipheimer et al., 2019). These evidence of crosstalk between ROS and protein synthesis may help to elucidate the mechanism of $\mathrm{Cu}$ toxicity in C. neoformans.

Regarding the up-regulated protein degradation under $\mathrm{Cu}$ stress, the proteasome pathway is the principal route of intracellular protein degradation (Rousseau and Bertolotti, 2018). We showed that proteasome activity was increased during $\mathrm{Cu}$ stress and induced by ROS accumulation. The fact that the effect of $\mathrm{Cu}$ stress on growth restriction in C. neoformans was partially ameliorated by the proteasome inhibitor MG132 suggested that ubiquitin-mediated degradation underlies the growth restriction. The crosstalk between $\mathrm{Cu}$ or $\mathrm{Cu}$-induced ROS and the proteasome pathway in C. neoformans remains unclear. However, clues can be found in several studies. The accumulation of ubiquitinated proteins alters the cellular redox state, leading to AMPK activation (Jiang et al., 2015). Additionally, cAMP/PKA can protect against oxidative damage (Geddes et al., 2016). Our study provides the perspective in that the inhibition of ubiquitinproteasome pathway help to recover C. neoformans proliferation during high $\mathrm{Cu}$ or ROS stress. The protective function of MG132 may dues to the inhibition of degradation of key regulatory factors, 


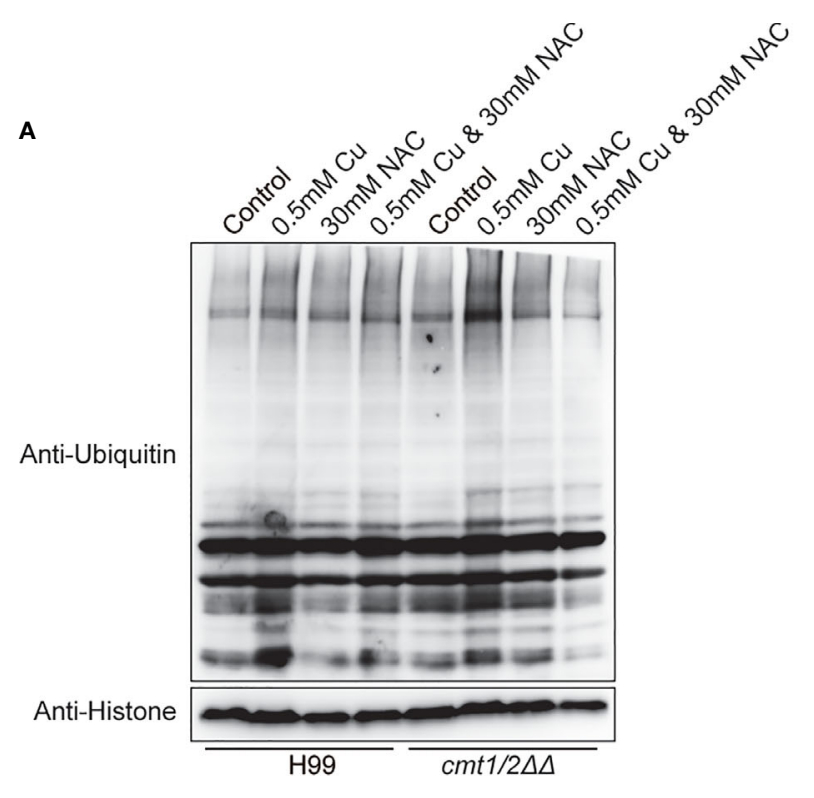

B

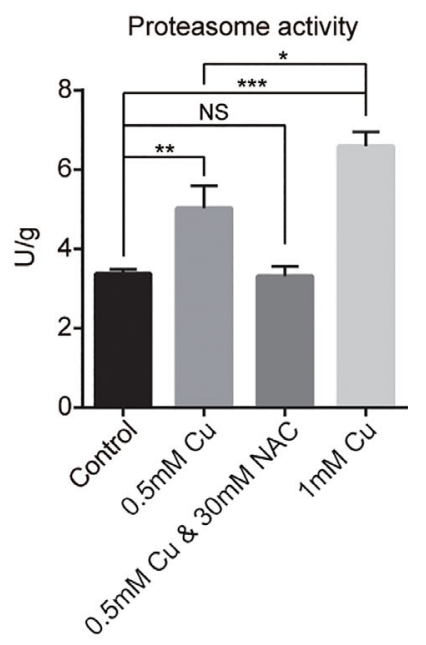

C

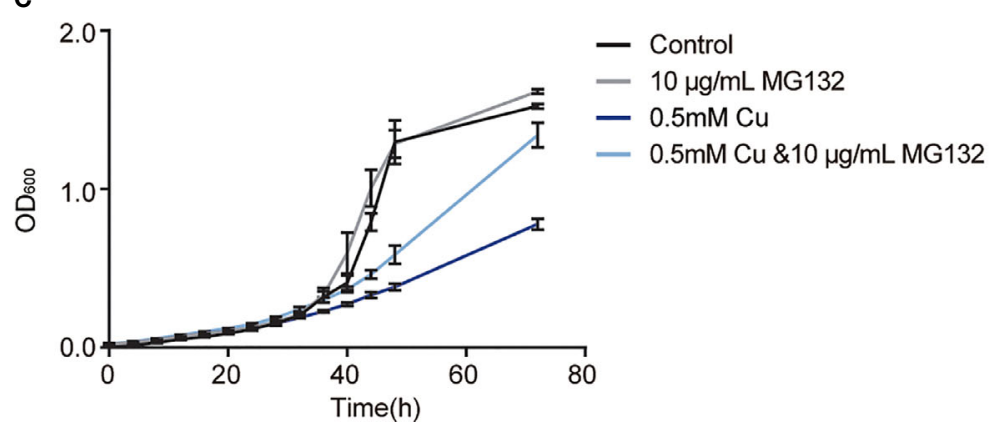

FIGURE 6 | Ubiquitin-mediated proteolysis under copper (Cu) stress. (A) Western blot analysis of ubiquitinated proteins in the wild-type strain H99 and Cu-sensitive mutant $\mathrm{cmt1} / 2 \Delta \Delta$. Cells were treated with $0.5 \mathrm{mM} \mathrm{Cu}, 30 \mathrm{mM}$ NAC, $0.5 \mathrm{mM}$ Cu plus $30 \mathrm{mM}$ NAC, respectively in yeast extract peptone dextrose (YPD) medium. The grayscale of the bands is positively correlated with the relative expression of ubiquitination level of total proteins. (B) Proteasome activity assay of $\mathrm{cmt1} / 2 \Delta \Delta$ under $\mathrm{Cu}$ stress. cmt1/2 $\Delta \Delta$ mutant was induced by $0.5 \mathrm{mM} \mathrm{Cu}, 1 \mathrm{mM} \mathrm{Cu}$, or both $0.5 \mathrm{mM} \mathrm{Cu}$ and $30 \mathrm{mM} \mathrm{N}$-acetylcysteine (NAC) in YPD medium for $4 \mathrm{~h}$. ${ }^{*} \mathrm{p}$-value $<0.05$, ${ }^{* *} \mathrm{p}$-value $<0.01,{ }^{* \star *} p$-value $<0.005(n=3)$. NS, not significant. The fluorescence of the samples was quantified using the standard substance in the proteasome activity assay kit. Proteasome activity is shown in $\mathrm{U} / \mathrm{g}$ protein. Histone was used as an internal reference. (C) Growth (based on optical density at $600 \mathrm{~nm}$ ) of $\mathrm{cmt} 1 / 2 \Delta \Delta$ under $\mathrm{Cu}$ stress was affected by the proteasome inhibitor MG132. $\mathrm{cmt1} / 2 \Delta \Delta$ was incubated in YPD medium with or without $0.5 \mathrm{mM} \mathrm{Cu}$ and $10 \mu \mathrm{g} / \mathrm{mL} \mathrm{MG132}$ ( $(\mathrm{n}=3)$.

such as heat shock factors. And the accumulation of abnormal proteins caused rapid increases in mRNA levels. This may induce the protective factors expression during recovery process (Bush et al., 1997; Lee and Goldberg, 1998; Mazroui et al., 2007).

Inhibition of protein degradation could not completely offset $\mathrm{Cu}$ toxicity. We identified changes in branched-chain amino acid biosynthesis, mitochondrial transmembrane transport, and ATP-binding cassettes in response to $\mathrm{Cu}$ stress, which may be associated with energy metabolism. Their relationship of these changes to $\mathrm{Cu}$ toxicity requires further study.

In summary, we assessed the global proteins response to $\mathrm{Cu}$ toxicity in C. neoformans. The core data may provide a theoretical basis for the development of antifungal drugs targeting the $\mathrm{Cu}$ ion metabolism pathway, to shorten treatment courses and increase therapeutic options. Continued attention should be paid to the characterization of the roles of specific proteins in virulence and the molecular mechanisms based on proteomic data.

\section{DATA AVAILABILITY STATEMENT}

The datasets presented in this study can be found in online repositories. The names of the repository/repositories and accession number(s) can be found below: ProteomeXchange Consortium (http://proteomecentral.proteomexchange.org) via the iProX partner repository with the dataset identifier PXD024098.

\section{AUTHOR CONTRIBUTIONS}

TS, YJL, YXL, HL, and YN performed the experiments. TS and CD designed the study. TS, YJL, HL, YG, and JW analyzed the 
data. TS, YX, CD provided equipment and funding. TS, YXL, and $\mathrm{CD}$ composed the manuscript. All authors contributed to the article and approved the submitted version.

\section{FUNDING}

This research was supported by the National Natural Science Foundation of China (81801989 to TS), the Beijing Natural Science Foundation (5184037 to TS 7204288 to YXL), the Fundamental Research Funds for the Central Universities (3332018024 to TS), the China Postdoctoral Science Foundation

\section{REFERENCES}

Aguirre, J., Hansberg, W., and Navarro, R. (2006). Fungal Responses to Reactive Oxygen Species. Med. Mycol. 44 (Supplement_1), S101-S107. doi: 10.1080/ 13693780600900080

Agustinho, D. P., Miller, L. C., Li, L. X., and Doering, T. L. (2018). Peeling the Onion: The Outer Layers of Cryptococcus Neoformans. Mem Inst Oswaldo Cruz 113 (7), e180040. doi: 10.1590/0074-02760180040

Andreou, M., Cogliati, M., Kolonitsiou, F., Stroumpos, C., Stamouli, V., Ravazoula, P., et al. (2020). Cryptococcus Gattii Infection in an Immunocompetent Host in Greece. Med. Mycol Case Rep. 27, 1-3. doi: 10.1016/j.mmcr.2019.12.002

Antsotegi-Uskola, M., Markina-Inarrairaegui, A., and Ugalde, U. (2020). New Insights Into Copper Homeostasis in Filamentous Fungi. Int. Microbiol. 23 (1), 65-73. doi: 10.1007/s10123-019-00081-5

Ashburner, M., Ball, C. A., Blake, J. A., Botstein, D., and Cherry, J. M. (2000). Gene Ontology: Tool for the Unification of Biology. The Gene Ontology Consortium. Nat. Genet. 25 (1), 25-29. doi: 10.1038/75556

Ballou, E. R., and Wilson, D. (2016). The Roles of Zinc and Copper Sensing in Fungal Pathogenesis. Curr. Opin. Microbiol. 32, 128-134. doi: 10.1016/j.mib.2016.05.013

Besold, A. N., Culbertson, E. M., and Culotta, V. C. (2016). The Yin and Yang of Copper During Infection. J. Biol. Inorg. Chem. 21 (2), 137-144. doi: 10.1007/s00775-016-1335-1

Brancaccio, D., Gallo, A., Piccioli, M., Novellino, E., Ciofi-Baffoni, S., and Banci, L. (2017). [4fe-4s] Cluster Assembly in Mitochondria and Its Impairment by Copper. J. Am. Chem. Soc. 139 (2), 719-730. doi: 10.1021/jacs.6b09567

Bremner, I. (1998). Manifestations of Copper Excess. Am. J. Clin. Nutr. 67 (5 Suppl), 1069S-1073S. doi: 10.1093/ajcn/67.5.1069S

Bush, K. T., Goldberg, A. L., and Nigam, S. K. (1997). Proteasome Inhibition Leads to a Heat-Shock Response, Induction of Endoplasmic Reticulum Chaperones, and Thermotolerance. J. Biol. Chem. 272 (14), 9086-9092. doi: 10.1074/jbc.272.14.9086

Cao, L. L., Shen, C., and Zhu, W. G. (2016). Histone Modifications in DNA Damage Response. Sci. China Life Sci. 59 (3), 257-270. doi: 10.1007/s11427-016-5011-z

Chaturvedi, K. S., and Henderson, J. P. (2014). Pathogenic Adaptations to Host-Derived Antibacterial Copper. Front. Cell Infect. Microbiol. 4, 3. doi: 10.3389/fcimb.2014.00003

Cui, Y., Zhao, Y., Tian, Y., Zhang, W., Lü, X., and Jiang, X. (2012). The Molecular Mechanism of Action of Bactericidal Gold Nanoparticles on Escherichia Coli. Biomaterials 33 (7), 2327-2333. doi: 10.1016/j.biomaterials.2011.11.057

Datta, K., Bartlett, K. H., Baer, R., Byrnes, E., and Marr, K. A. (2009). Spread of Cryptococcus Gattii Into Pacific Northwest Region of the United States. Emerg. Infect. Dis. 15 (8), 1185-1191. doi: 10.3201/eid1508.081384

Ding, C., Yin, J., Tovar, E. M., Fitzpatrick, D. A., Higgins, D. G., and Thiele, D. J. (2011). The Copper Regulon of the Human Fungal Pathogen Cryptococcus Neoformans H99. Mol. Microbiol. 81 (6), 1560-1576. doi: 10.1111/j.1365-2958.2011.07794.x

Ding, C., Yin, J., Tovar, E., Fitzpatrick, D. A., and Thiele, D. (2013). Cryptococcus Neoformans Copper Detoxification Machinery is Critical for Fungal Virulence. Cell Host Microbe 13 (3), 265-276. doi: 10.1016/j.chom.2013.02.002

Ding, C., Festa, R. A., Sun, T., and Wang, Z. (2014). Iron and Copper as Virulence Modulators in Human Fungal Pathogens. Mol. Microbiol. 93 (1), 10-23. doi: $10.1111 / \mathrm{mmi} .12653$

Gaetke, L. M., and Chow, C. K. (2003). Copper Toxicity, Oxidative Stress, and Antioxidant Nutrients. Toxicology 189 (1-2), 147-163. doi: 10.1016/S0300483X(03)00159-8
(2021M693520 to HL), the National Natural Science Foundation of China (31870140 to CD), Liaoning Revitalization Talents Program (XLYC1807001), Beijing Key Laboratory for Mechanisms Research and Precision Diagnosis of Invasive Fungal Diseases.

\section{SUPPLEMENTARY MATERIAL}

The Supplementary Material for this article can be found online at: https://www.frontiersin.org/articles/10.3389/fcimb.2021. 662404/full\#supplementary-material

Gaetke, L. M., Chow-Johnson, H. S., and Chow, C. K. (2014). Copper: Toxicological Relevance and Mechanisms. Arch. Toxicol. 88 (11), 1929-1938. doi: 10.1007/s00204-014-1355-y

Garcia-Santamarina, S., Uzarska, M. A., Festa, R. A., Lill, R., Thiele, D. J., and Lorenz, M. (2017). Cryptococcus Neoformans Iron-Sulfur Protein Biogenesis Machinery Is a Novel Layer of Protection Against Cu Stress. mBio 8 (5). doi: 10.1128/mBio.01742-17

Garcia-Santamarina, S., Festa, R. A., Smith, A. D., Yu, C., Probst, C., Chen, D., et al. (2018). Genome-Wide Analysis of the Regulation of Cu Metabolism in Cryptococcus Neoformans. Mol. Microbiol. 108 (5), 473-494. doi: 10.1111/ mmi.13960

Garcia-Santamarina, S., and Thiele, D. J. (2015). Copper at the Fungal PathogenHost Axis. J. Biol. Chem. 290 (31), 18945-18953. doi: 10.1074/jbc.R115.649129

Garcia Silva-Bailao, M., Lobato Potenciano da Silva, K., Raniere Borges Dos Anjos, L., de Sousa Lima, P., de Melo Teixeira, M., Maria de Almeida Soares, C., et al. (2018). Mechanisms of Copper and Zinc Homeostasis in Pathogenic Black Fungi. Fungal Biol. 122 (6), 526-537. doi: 10.1016/j.funbio.2017.12.002

Gardner, S. P., and Olson, J. W. (2018). Interaction of Copper Toxicity and Oxidative Stress in Campylobacter Jejuni. J. Bacteriol. 200 (21), e00208-18. doi: 10.1128/JB.00208-18

Geddes, J. M., Caza, M., Croll, D., Stoynov, N., Foster, L. J., and Kronstad, J. W. (2016). Analysis of the Protein Kinase A-Regulated Proteome of Cryptococcus Neoformans Identifies a Role for the Ubiquitin-Proteasome Pathway in Capsule Formation. mBio 7 (1), e01862-e01815. doi: 10.1128/mBio.01862-15

German, N., Luthje, F., Hao, X., Ronn, R., and Rensing, C. (2016). Microbial Virulence and Interactions With Metals. Prog. Mol. Biol. Transl. Sci. 142, 27 49. doi: 10.1016/bs.pmbts.2016.05.010

Gotz, S., Garcia-Gomez, J. M., Terol, J., Williams, T. D., Nagaraj, S. H., Nueda, M. J., et al. (2008). High-Throughput Functional Annotation and Data Mining With the Blast2GO Suite. Nucleic Acids Res. 36 (10), 3420-3435. doi: 10.1093/ nar/gkn176

Grass, G., Rensing, C., and Solioz, M. (2011). Metallic Copper as an Antimicrobial Surface. Appl. Environ. Microbiol. 77 (5), 1541-1547. doi: 10.1128/AEM.02766-10

Hans, M., Mathews, S., Mücklich, F., and Solioz, M. (2015). Physicochemical Properties of Copper Important for its Antibacterial Activity and Development of a Unified Model. Biointerphases 11 (1), 018902. doi: 10.1116/1.4935853

Hood, M. I., and Skaar, E. P. (2012). Nutritional Immunity: Transition Metals at the Pathogen-Host Interface. Nat. Rev. Microbiol. 10 (8), 525-537. doi: 10.1038/nrmicro2836

Jiang, N., Liu, X., Yang, J., Li, Z., Pan, J., and Zhu, X. (2011). Regulation of Copper Homeostasis by Cuf1 Associates With Its Subcellular Localization in the Pathogenic Yeast Cryptococcus Neoformans H99. FEMS Yeast Res. 11 (5), 440-448. doi: 10.1111/j.1567-1364.2011.00733.x

Jiang, S., Park, D. W., Gao, Y., Ravi, S., and Zmijewski, J. W. (2015). Participation of Proteasome-Ubiquitin Protein Degradation in Autophagy and the Activation of AMP-Activated Protein Kinase. Cell Signal 27 (6), 1186-1197. doi: 10.1016/j.cellsig.2015.02.024

Jiang, Y., Bian, Y., Lian, N., Wang, Y., and Yu, Y. (2020). iTRAQ-Based Quantitative Proteomic Analysis of Intestines in Murine Polymicrobial Sepsis With Hydrogen Gas Treatment. Drug Des. Devel. Ther. 14, 48854900. doi: 10.2147/DDDT.S271191 
Kanehisa, M., Goto, S., Sato, Y., Furuchimi, M., and Tanabe, M. (2012). KEGG for Integration and Interpretation of Large-Scale Molecular Data Sets. Nucleic Acids Res. 40 (Database issue), D109-D114. doi: 10.1093/nar/gkr988

Karlin, K. D. (1993). Metalloenzymes, Structural Motifs, and Inorganic Models. Science 261 (5122), 701-708. doi: 10.1126/science.7688141

Kaur, K., Sharma, A., Capalash, N., and Sharma, P. (2019). Multicopper Oxidases: Biocatalysts in Microbial Pathogenesis and Stress Management. Microbiol. Res. 222, 1-13. doi: 10.1016/j.micres.2019.02.007

Khera, D., Sharma, B., and Singh, K. (2016). Copper Deficiency as a Cause of Neutropenia in a Case of Coeliac Disease. BMJ Case Rep. 2016, bcr2016214874. doi: 10.1136/bcr-2016-214874

Kosman, D. J. (2018). For Cryptococcus Neoformans, Responding to the Copper Status in a Colonization Niche is Not Just About Copper. Mol. Microbiol. 108 (5), 463-466. doi: 10.1111/mmi.13963

Kronstad, J. W., Attarian, R., Cadieux, B., Choi, J., D'Souza, C. A., Griffiths, E. J., et al. (2011). Expanding Fungal Pathogenesis: Cryptococcus Breaks Out of the Opportunistic Box. Nat. Rev. Microbiol. 9 (3), 193-203. doi: 10.1038/nrmicro2522

Lee, D. H., and Goldberg, A. L. (1998). Proteasome Inhibitors: Valuable New Tools for Cell Biologists. Trends Cell Biol. 8 (10), 397-403. doi: 10.1016/S0962-8924 (98)01346-4

Leipheimer, J., Bloom, A., Campomizzi, C. S., Salei, Y., and Panepinto, J. C. (2019). Translational Regulation Promotes Oxidative Stress Resistance in the Human Fungal Pathogen Cryptococcus Neoformans. mBio 10 (6). doi: 10.1128/mBio.02143-19

Li, H., Li, Y., Sun, T., Du, W., Li, C., Suo, C., et al. (2019). Unveil the Transcriptional Landscape at the Cryptococcus-Host Axis in Mice and Nonhuman Primates. PloS Negl. Trop. Dis. 13 (7), e0007566. doi: 10.1371/journal.pntd.0007566

Li, C., Li, Y., and Ding, C. (2019). The Role of Copper Homeostasis at the HostPathogen Axis: From Bacteria to Fungi. Int. J. Mol. Sci. 20 (1), 175. doi: 10.3390/ijms20010175

Liszczak, G., Diehl, K. L., Dann, G. P., and Muir, T. W. (2018). Acetylation Blocks DNA Damage-Induced Chromatin ADP-Ribosylation. Nat. Chem. Biol. 14 (9), 837-840. doi: 10.1038/s41589-018-0097-1

Macomber, L., Rensing, C., and Imlay, J. A. (2007). Intracellular Copper Does Not Catalyze the Formation of Oxidative DNA Damage in Escherichia Coli. J. Bacteriol 189 (5), 1616-1626. doi: 10.1128/JB.01357-06

Manes, N. P., and Nita-Lazar, A. (2018). Application of Targeted Mass Spectrometry in Bottom-Up Proteomics for Systems Biology Research. J. Proteomics 189, 75-90. doi: 10.1016/j.jprot.2018.02.008

Maziarz, E. K., and Perfect, J. R. (2016). Cryptococcosis. Infect. Dis. Clin. North Am. 30 (1), 179-206. doi: 10.1016/j.idc.2015.10.006

Mazroui, R., Marco, S. D., Kaufman, R. J., and Gallouzi, I. E. (2007). Inhibition of the Ubiquitin-Proteasome System Induces Stress Granule Formation. Mol. Biol. Cell 18 (7), 2603-2618. doi: 10.1091/mbc.e06-12-1079

Nesvizhskii, A. I., Keller, A., Kolker, E., and Aebersold, R. (2003). A Statistical Model for Identifying Proteins by Tandem Mass Spectrometry. Anal. Chem. 75 (17), 4646-4658. doi: 10.1021/ac0341261

Neyrolles, O., Mintz, E., and Catty, P. (2013). Zinc and Copper Toxicity in Host Defense Against Pathogens: Mycobacterium Tuberculosis as a Model Example of an Emerging Paradigm. Front. Cell. Infection Microbiol. 3, 89. doi: 10.3389/ fcimb.2013.00089

Perez-Gallardo, R. V., Briones, L. S., Diaz-Perez, A. L., Gutierrez, S., RodríguezZavala, J. S., and Campos-Garcia, J. (2013). Reactive Oxygen Species Production Induced by Ethanol in Saccharomyces Cerevisiae Increases Because of a Dysfunctional Mitochondrial Iron-Sulfur Cluster Assembly System. FEMS Yeast Res. 13 (8), 804-819. doi: 10.1111/1567-1364.12090

Raffa, N., Osherov, N., and Keller, N. P. (2019). Copper Utilization, Regulation, and Acquisition by Aspergillus Fumigatus. Int. J. Mol. Sci. 20 (8), 1980. doi: 10.3390/ijms20081980

Raja, M. R., Waterman, S. R., Qiu, J., Bleher, R., Williamson, P. R., and O'Halloran, T. V. (2013). A Copper Hyperaccumulation Phenotype Correlates With Pathogenesis in Cryptococcus Neoformans. Metallomics 5 (4), 363-371. doi: 10.1039/c3mt20220h

Rousseau, A., and Bertolotti, A. (2018). Regulation of Proteasome Assembly and Activity in Health and Disease. Nat. Rev. Mol. Cell Biol. 19 (11), 697-712. doi: 10.1038/s41580-018-0040-z

Shen, Q., Beucler, M. J., Ray, S. C., and Rappleye, C. A. (2018). Macrophage Activation by IFN-Gamma Triggers Restriction of Phagosomal Copper From Intracellular Pathogens. PloS Pathog. 14 (11), e1007444. doi: 10.1371/ journal.ppat.1007444
Smith, A. D., Logeman, B. L., and Thiele, D. J. (2017). Copper Acquisition and Utilization in Fungi. Annu. Rev. Microbiol. 71, 597-623. doi: 10.1146/annurev-micro-030117-020444 Sun, T. S., Ju, X., Gao, H. L., Wang, T., Thiele, D. J., Li, J. Y., et al. (2014). Reciprocal Functions of Cryptococcus Neoformans Copper Homeostasis Machinery During Pulmonary Infection and Meningoencephalitis. Nat. Commun. 5, 5550. doi: 10.1038/ncomms6550

Sun, T., Li, X., Song, W., Yu, S., and Xu, Y. (2021). Metabolomic Alterations Associated With Copper Stress in Cryptococcus Neoformans. Future Microbiol. 16, 305-316. doi: 10.2217/fmb-2020-0290

Tan, G., Jing, Y., Tang, L., Jin, Z., and Ding, H. (2017). Anaerobic Copper Toxicity and Iron-Sulfur Cluster Biogenesis in Escherichia Coli. Appl. Environ. Microbiol. 83 (16). doi: 10.1128/AEM.00867-17

Thorslund, T., Ripplinger, A., Hoffmann, S., Wild, T., Uckelmann, M., Villumsen, B., et al. (2015). Histone H1 Couples Initiation and Amplification of Ubiquitin Signalling After DNA Damage. Nature 527 (7578), 389-393. doi: 10.1038/nature15401

Topf, U., Suppanz, I., Samluk, L., Wrobel, L., Bser, A., Sakowska, P., et al. (2018). Quantitative Proteomics Identifies Redox Switches for Global Translation Modulation by Mitochondrially Produced Reactive Oxygen Species. Nat. Commun. 9 (1), 324. doi: 10.1038/s41467-017-02694-8

Uckelmann, M., and Sixma, T. K. (2017). Histone Ubiquitination in the DNA Damage Response. DNA Repair (Amst) 56, 92-101. doi: 10.1016/j.dnarep.2017.06.011

Vimbela, G. V., Ngo, S. M., Fraze, C., Yang, L., and Stout, D. A. (2017). Antibacterial Properties and Toxicity From Metallic Nanomaterials. Int. J. Nanomedicine 12, 3941-3965. doi: 10.2147/IJN.S134526

Vincent, M., Duval, R. E., Hartemann, P., and Engels-Deutsch, M. (2018). Contact Killing and Antimicrobial Properties of Copper. J. Appl. Microbiol. 124 (5), 1032-1046. doi: 10.1111/jam.13681

White, C., Lee, J., Kambe, T., Fritsche, K., and Petris, M. J. (2009). A Role for the ATP7A Copper-Transporting ATPase in Macrophage Bactericidal Activity. J. Biol. Chem. 284 (49), 33949-33956. doi: 10.1074/jbc.M109.070201

Wiemann, P., Perevitsky, A., Lim, F. Y., Shadkchan, Y., Knox, B. P., Figueora, J. L., et al. (2017). Aspergillus Fumigatus Copper Export Machinery and Reactive Oxygen Intermediate Defense Counter Host Copper-Mediated Oxidative Antimicrobial Offense. Cell Rep. 19 (10), 2174-2176. doi: 10.1016/j.celrep.2017.05.075

Willi, J., Küpfer, P., Evéquoz, D., Fernandez, G., Katz, A., Leumann, C., et al. (2018). Oxidative Stress Damages rRNA Inside the Ribosome and Differentially Affects the Catalytic Center. Nucleic Acids Res. 46 (4), 1945-1957. doi: 10.1093/nar/gkx1308

Wilson, D. N. (2014). Ribosome-Targeting Antibiotics and Mechanisms of Bacterial Resistance. Nat. Rev. Microbiol. 12 (1), 35-48. doi: 10.1038/nrmicro3155

Youseff, B. H., Holbrook, E. D., Smolnycki, K. A., Rappleye, C. A., and Andrianopoulos, A. (2012). Extracellular Superoxide Dismutase Protects Histoplasma Yeast Cells From Host-Derived Oxidative Stress. PloS Pathog. 8 (5), e1002713. doi: 10.1371/journal.ppat.1002713

Yu, G., Wang, L. G. , Han, Y., and He, Q. Y. (2012). Clusterprofiler: An R Package for Comparing Biological Themes Among Gene Clusters. OMICS 16 (5), 284-287. doi: 10.1089/omi.2011.0118

Zhu, M., Li, Y., Ding, C., Wang, J., and Wang, P. (2020). Proteomic Profiling Change and Its Implies in the Early Mycosis Fungoides (MF) Using Isobaric Tags for Relative and Absolute Quantification (iTRAQ). BioMed. Res. Int. 2020, 9237381. doi: 10.1155/2020/9237381

Conflict of Interest: The authors declare that the research was conducted in the absence of any commercial or financial relationships that could be construed as a potential conflict of interest.

Publisher's Note: All claims expressed in this article are solely those of the authors and do not necessarily represent those of their affiliated organizations, or those of the publisher, the editors and the reviewers. Any product that may be evaluated in this article, or claim that may be made by its manufacturer, is not guaranteed or endorsed by the publisher.

Copyright $\odot 2021$ Sun, $L i, L i, L i$, Gong, Wu, Ning, Ding and $X u$. This is an openaccess article distributed under the terms of the Creative Commons Attribution License (CC BY). The use, distribution or reproduction in other forums is permitted, provided the original author(s) and the copyright owner(s) are credited and that the original publication in this journal is cited, in accordance with accepted academic practice. No use, distribution or reproduction is permitted which does not comply with these terms. 